\title{
Comparative Analysis of Phytophthora Genes Encoding Secreted Proteins Reveals Conserved Synteny and Lineage-Specific Gene Duplications and Deletions
}

\author{
Rays H. Y. Jiang, ${ }^{1}$ Brett M. Tyler, ${ }^{1,2}$ and Francine Govers ${ }^{1}$ \\ ${ }^{1}$ Laboratory of Phytopathology, Plant Sciences Group, Wageningen University, Binnenhaven 5, NL-6709 PD Wageningen \\ and Graduate School Experimental Plant Sciences, The Netherlands; ${ }^{2}$ Virginia Bioinformatics Institute, Virginia Polytechnic \\ Institute and State University, Blacksburg 24061, U.S.A.
}

Submitted 30 March 2006. Accepted 31 July 2006.

Comparative analysis of two Phytophthora genomes revealed overall colinearity in four genomic regions consisting of a 1.5-Mb sequence of Phytophthora sojae and a $0.9-\mathrm{Mb}$ sequence of $P$. ramorum. In these regions with conserved synteny, the gene order is largely similar; however, genome rearrangements also have occurred. Deletions and duplications often were found in association with genes encoding secreted proteins, including effectors that are important for interaction with host plants. Among secreted protein genes, different evolutionary patterns were found. Elicitin genes that code for a complex family of highly conserved Phytophthora-specific elicitors show conservation in gene number and order, and often are clustered. In contrast, the race-specific elicitor gene $A v r 1 b$-1 appeared to be missing from the region with conserved synteny, as were its five homologs that are scattered over the four genomic regions. Some gene families encoding secreted proteins were found to be expanded in one species compared with the other. This could be the result of either repeated gene duplications in one species or specific deletions in the other. These different evolutionary patterns may shed light on the functions of these secreted proteins in the biology and pathology of the two Phytophthora spp.

Additional keywords: comparative genomics, RXLR-dEER.

Conserved synteny refers to conserved gene order between orthologous chromosomal segments of two or more organisms. In all kingdoms of life, comparative genomics has revealed large blocks of conserved synteny between related species (Frazer et al. 2003; McCouch 2001). Blocks of conserved synteny can be interrupted by insertions or deletions due to genome rearrangements and, sometimes, genes with specific functions may be more prone to genome rearrangements than others. When comparing, for example, a pathogen with a nonpathogen, genome regions rich in rearrangements can be ideal to find pathogenesis-related genes. A nearly perfect conserved synteny was found between the bacterial pathogen Listeria monocytogenes that causes foodborne infections and the closely related nonpathogenic species L. innocua. Species-specific sequences, how-

Corresponding author: F. Govers; Telephone: +31317 483138; Fax: +31 317 483412; E-mail: Francine.Govers@ wur.nl

* The $e$-Xtra logo stands for "electronic extra" and indicates the HTML abstract available on-line contains supplemental material not included in the print edition. Two tables and a supplemental figure appear on-line. ever, were found at a locus required for chemotaxis and motility, which may explain the different needs of parasitic and free-living life styles (Buchrieser et al. 2003). Also, in eukaryotic parasites, comparative genomics revealed genome rearrangements related to virulence-associated genes. The striking conserved synteny between the human malaria parasite Plasmodium falciparum and the rodent malaria parasite $P$. yoelii is interrupted by only a few genes, and these speciesspecific genes frequently are found to trigger host immune responses (Carlton et al. 2005). Three related protozoan pathogens that diverged 200 to 500 million years ago, Trypanosoma brucei, T. cruzi, and Leishmania major, show large blocks of conserved synteny but have species-specific genes that are associated with expansions of retroelements, structural RNAs, and surface antigen gene families (El-Sayed et al. 2005). Because of the flexibility required for the interaction with hosts, rearrangements in regions containing pathogenicity or virulence genes might be more easily fixed due to selection pressure.

In 2004, the first two Phytophthora genomes were sequenced at the Joint Genome Institute (JGI). Phytophthora spp. are fungal-like organisms classified as oomycetes and comprise many notorious pathogens of crops, trees, and ornamentals (Erwin and Ribeiro 1996). The majority of the Phytophthora taxa form a monophyletic group and their phylogenetic affinity suggests that different Phytophthora spp. may be at a proper evolutionary distance to search for blocks of conserved synteny and genome rearrangements (Cooke et al. 2000). The two sequenced species are Phytophthora sojae, an economically important species responsible for yield losses in soybean due to stem and root rot, and P. ramorum, a recently identified species that causes sudden oak death and is disastrous for oak trees on the west coast of the United States (Rizzo et al. 2004). $P$. sojae and $P$. ramorum differ in genome size (95 versus 65 $\mathrm{Mb}$ ), sexual behavior (homothallic versus heterothallic), and host specificity (single host versus broad host range). The number of genes predicted by the JGI annotation pipeline is 19,027 in $P$. sojae and 15,743 in $P$. ramorum, the majority of which have a homolog in the other species (Tyler et al. 2006). Whole-genome DNA alignment demonstrated a high level of similarity between the two species, with over $75 \%$ of the exons covered by the alignment (Tyler et al. 2006). Because the two genomes show extensive gene colinearity, comparative analysis with the aim to locate genome rearrangements becomes feasible. Genome rearrangement patterns may explain aspects of distinct pathogenicity properties of individual Phytophthora spp.

Several proteins secreted by phytopathogenic fungi and oomycetes are known to play a role in pathogenicity. During in- 
fection and colonization, these extracellular effectors are secreted into the plant apoplast and some of them are thought to be delivered into the host cytoplasm to promote the infection process (Birch et al. 2006; Kamoun 2006). However, if plants are able to recognize these effectors, defense responses, including a form of programmed cell death known as the hypersensitive response, can be triggered and infection can be halted (van't Slot and Knogge 2002). Effectors that are able to elicit host responses are termed elicitors. From an evolutionary perspective, effectors can be classified according to the time of their emergence (Jiang et al. 2006a). Those that are highly conserved across all Phytophthora spp. are likely to have a basal role in the interaction with the host. In contrast, speciesspecific effectors, that probably evolved more recently, are likely to contribute to the more unique features exemplified in, for example, avirulence on specific host plants.

For comparative analysis, we selected four regions in the genome of $P$. sojae that contain genes encoding elicitors, thereby focusing on two groups of elicitors that have a different phylogenetic distribution: elicitins representing genus-specific elicitors and AVR1b-1(-like) proteins representing species-specific elicitors. Elicitins are ubiquitous within the Phytophthora genus, and unique to Phytophthora and some closely related Pythium spp. They belong to an extensive gene family comprising elicitin (eli) and elicitin-like (ell) genes (Jiang et al. 2006a). ELIs share a highly conserved 98 amino-acid elicitin domain with six cysteine residues involved in the formation of disulfide bonds. In ELLs, the elicitin domain is more variable in both length and sequence; however, in each of the 13 ELI clades, the six cysteine residues have their clade-specific spacing pattern. The eli and ell genes are highly conserved between Phytophthora spp. and occur mostly in clusters distributed over the genome (Jiang et al. 2006a). ELIs induce defense responses in plants, in particular in Nicotiana spp. (Kamoun et al. 1998; Ricci et al. 1992) and INF1, the most abundant secreted ELI from the late-blight pathogen $P$. infestans, has been proposed to be a determinant of nonhost resistance in Nicotiana benthamiana (Kamoun et al. 1998). Their intrinsic biological function generally is thought to be related to lipid binding, processing, or both. One of the ELIs is known to bind ergosterol and to function as a sterol-carrier protein (Mikes et al. 1997; Vauthrin et al. 1999), whereas another one was shown to have phospholipase activity (Nespoulous et al. 1999). AVR1b-1 belongs to a group of elicitors that are species specific (Shan et al. 2004). The avirulence gene $A v r l b-1$ in $P$. sojae does not belong to any highly conserved gene family and lacks highly similar homologs in other species. AVR1b-1 is responsible for the specific gene-for-gene interaction between soybean isolines carrying the Rps 1 resistance gene and $P$. sojae strains carrying Avrlb-1 (Shan et al. 2004). The Avrlb-1 and $A v r l b$-1-like genes, also named avirulence homologs (Avh), belong to a superfamily of genes encoding secreted proteins with highly divergent sequences. Despite the sequence divergence, the encoded proteins do share common features: they are small in size and lack cysteine residues but, most importantly, they all bear an RXLR motif, a novel motif possessed by several characterized oomycete effectors (Rehmany et al. 2005); AVR1b-1-like proteins, in particular, have a conserved dEER sequence shortly after the RXLR motif and, therefore, the superfamily is designated as the RXLR-dEER family. In addition to $A v r l b-1$, this superfamily comprises three other, recently cloned oomycete $A v r$ genes that interact with their hosts according to the gene-for-gene model: Avr $3 a$ from $P$. infestans (Armstrong et al. 2005) and Atrl (Rehmany et al. 2005) and Atrl3 (Allen et al. 2004) from Hyaloperonospora parasitica.

Thus, elicitins and RXLR-dEER proteins differ in various respects, including degree of sequence conservation, phylogenetic distribution, and specificity of host interaction. It is not known whether the evolutionary processes that shaped these two types of elicitors are different, such as different selection and co-evolution with hosts. One way to answer this question would be through a thorough examination of the genomic locations of the elicitin and $A v r l b-1(-1 \mathrm{k}$ e) genes and comparison of these regions between different Phytophthora spp. In this study, we first examined whether eli, ell, Avrlb-1, and Avh genes in P. sojae and $P$. ramorum are located in blocks of conserved synteny. We then identified other secreted protein genes and gene families located in those blocks and characterized expansion and shrinkage patterns of the gene families. Finally, several gene insertions, deletions, and rearrangments were analyzed in more detail. This study presents a detailed investigation of the local colinearity between two Phytophthora genomes, and discusses the evolutionary dynamics of the different types of effector genes.

\section{RESULTS}

\section{Four regions of conserved synteny in $P$. sojae and $P$. ramorum.}

Of the four genomic $P$. sojae regions spanning the two groups of effector genes, region I contains the eli gene cluster comprising all four existing ELI clades, ELI-1 to ELI-4; region II contains a member of the ELL-13 clade; region III contains $A v r 1 b$-1; and region IV contains an $A v r 1 b$-1-like gene, a close homolog of $A v r l b-1$ designated as $P s A v h \_l$ (BLASTP $E$ value 4E-63) (Fig. 1A). Region I and region II are located on the same scaffold in $P$. sojae. Of the corresponding regions in $P$. ramorum, region III and region IV are located on the same scaffold. As described in the following sections, the four regions contain other secreted protein genes and gene families in addition to the eli, ell, and Avrlb-1(-like) genes and, as such, are representative examples to illustrate the genomic organization and context of secreted protein-encoding genes.

Region I in $P$. sojae is defined as a $761-\mathrm{kb}$ genomic region containing 15 clustered eli genes, among a total of 185 annotated genes. Phylogenetically inferred groups (PhIGs) (Dehal and Boore 2006) and BLAST analysis revealed a region of conserved synteny in $P$. ramorum spanning a $451-\mathrm{kb}$ sequence and containing 133 annotated genes. In all, 97 gene pairs can be assigned as orthologs based on the sharing of best reciprocal BLAST hits. Most of the 97 orthologous pairs show the same gene order and orientation, but reversals of position and orientation occasionally do occur; 3 pairs exhibit reversed position and 8 pairs have reversed orientation. Region I comprises a wide range of genes encoding proteins involved in various processes, such as signal transduction (cAMP-dependent kinase), cell metabolism (Acyl-CoA desaturase), and transport of metabolites (solute carrier). Region I also contains a number of putative effector genes. In addition to the elicitin genes, it contains genes coding for cutinases, histidine/proline (His/Pro)rich secreted proteins, and two $P$. ramorum Avrlb-1 homologs, designated PrAvh_1 and PrAvh_2.

Region II is a $390-\mathrm{kb}$ sequence from $P$. sojae that spans the ell13 gene cluster. BLAST comparison revealed a $241-\mathrm{kb}$ region of conserved synteny in $P$. ramorum, with 43 pairs of orthologous genes. With the exception of 10 reversals, gene order and orientation are largely conserved. Region II, much like region I, contains genes involved in various processes and, in particular, many genes encoding secreted cysteine (Cys)-rich proteins. It was estimated that $8 \%$ of the total number of genes in the two Phytophthora spp. codes for secreted proteins (Jiang 2006; Tyler et al. 2006). A $\chi^{2}$ analysis with one degree of freedom showed that region II contains significantly more secreted protein-encoding genes than expected based on a random distribution of genes over the genome $(P<0.05)$. 
Region III and region IV in $P$. sojae contain Avrlb-1 and $P s A v h \_1$, respectively. Region III has 33 orthologous pairs spanning $201 \mathrm{~kb}$ in $P$. sojae and $79 \mathrm{~kb}$ in $P$. ramorum, and region IV has 19 orthologous pairs distributed over $151 \mathrm{~kb}$ in P. sojae and $94 \mathrm{~kb}$ in P. ramorum (Fig. 1A). In these two regions, few reversals were found and they both show conserved synteny.

To visualize colinearity and compare gene rearrangements between these two genomes, dot plots were generated with the program PipMaker (Schwartz et al. 2000). In all four regions,
A

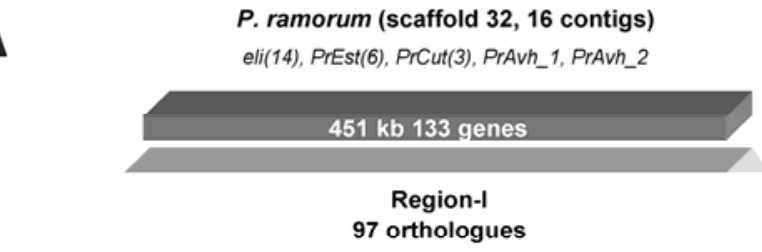

$P$. ramorum (scaffold 19,11 contigs) ell13(6), PrGPex1, PrGPex2

\section{1 kb 73 genes}

Region-II 43 orthologues

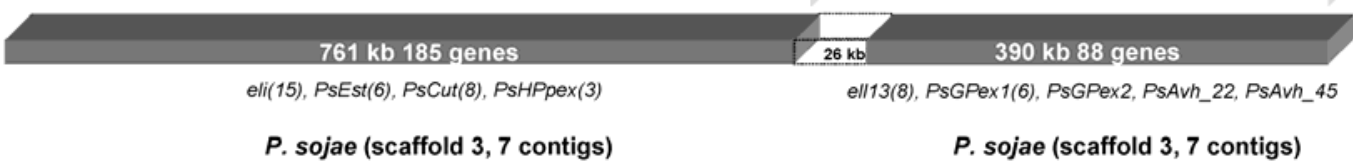

P. ramorum (scaffold 14, 1 contig) $\quad$ P. ramorum (scaffold 14, 8 contigs)

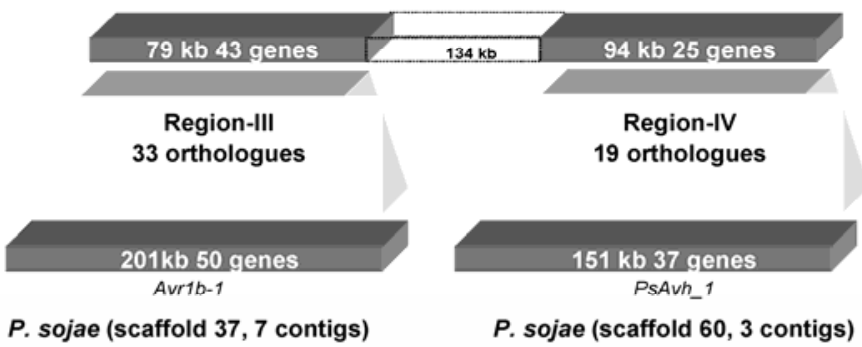

B

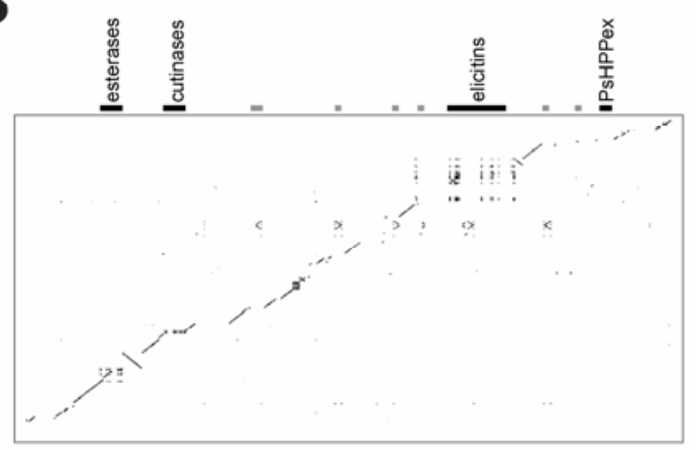

Region-I : X-axis $761 \mathrm{~kb} P$. sojae; Y-axis $451 \mathrm{~kb} P$. ramorum

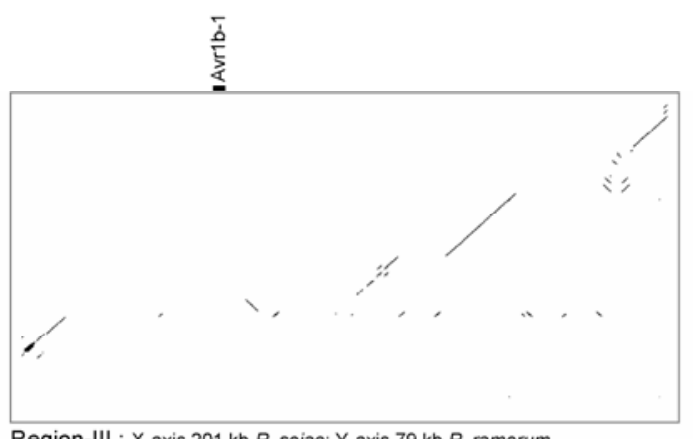

Region-III : X-axis $201 \mathrm{~kb}$ P. sojae; Y-axis $79 \mathrm{~kb}$ P. ramorum

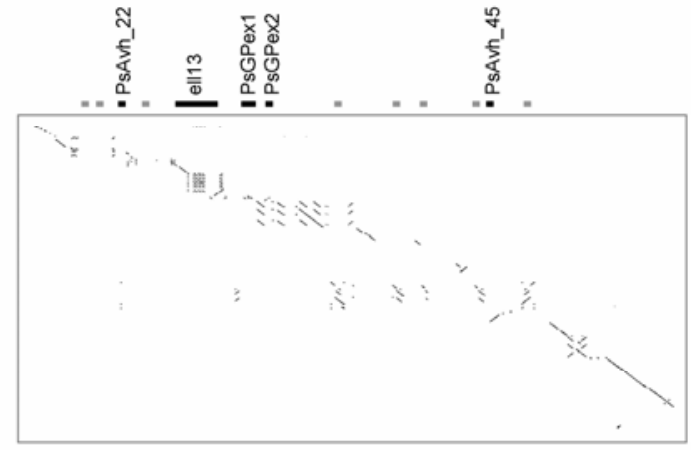

Region-II : X-axis $390 \mathrm{~kb} P$, sojae; $\mathrm{Y}$-axis $241 \mathrm{~kb} P$, ramorum

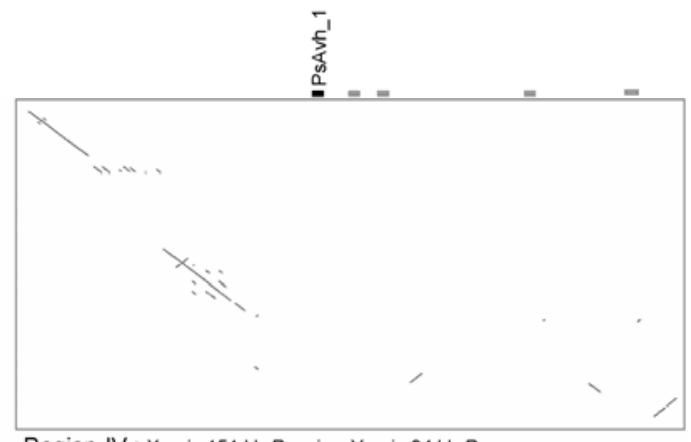

Region-IV : X-axis $151 \mathrm{~kb} P$. sojae; Y-axis $94 \mathrm{~kb} P$. ramorum

Fig. 1. A, Four syntenic regions used for comparative analysis. The chromosomal regions are shown in dark-gray bars and the syntenic regions are shown in light-gray blocks. The secreted protein genes located in these regions are indicated above or underneath. If there is more than one gene, the number of genes is indicated in parentheses. Region I and region II are on the same scaffold in Phytophthora sojae and region III and region IV are on the same scaffold in $P$. ramorum. B, PipMaker dot plots of four regions reveal colinearity and genome rearrangements between P. sojae (plotted horizontal) and P. ramorum (plotted vertical). The $P$. sojae genes and gene families that were analyzed in this study are shown along the top $X$ axis. Retrotransposon-like elements are indicated by gray lines along the top $X$ axis. Because of space limitations, only 18 of the 30 retrotransposon-like elements in $P$. sojae are indicated. Homology was plotted when at least $100 \mathrm{bp}$ aligned without a gap and the nucleotide identity was higher than $70 \%$. 
the discontinuous diagonal line emphasizes the conserved synteny between $P$. sojae and $P$. ramorum (Fig. 1B), and this conservation is concentrated mainly in the coding regions. Many of the short dotted lines that deviate from the main diagonal line represent various mobile elements. In the four regions, we found a total of 37 relatively intact retroelements (seven in $P$. ramorum and 30 in $P$. sojae) and none of them showed conserved gene order or orientation. The occurrence of major gene families is evident from multiple parallel lines at one position. Notably, the cutinase gene family in region I shows a higher copy number in $P$. sojae than in $P$. ramorum. In regions III and IV, there are large stretches that lack alignable homologous sequences, as shown by the gaps in the dot plots. The two RXLR-dEER family members Avrlb-1 and PsAvrh_l appear to reside in such gaps. This is described in more detail below.

Across all four regions, $1.50 \mathrm{Mb}$ of sequence in $P$. sojae is compared with $0.86 \mathrm{Mb}$ in $P$. ramorum. The 192 orthologous gene pairs represent $54 \%$ of all the genes present in the four examined regions in $P$. sojae and $68 \%$ of the genes defined in the regions of conserved synteny in $P$. ramorum. Apparently, more than half of the genes in these particular regions share orthology. The majority of the genes that have no ortholog within the four regions of conserved synteny have detectable homologs elsewhere in the genome (TBLASTN hit with $E$ value $<1 \mathrm{E}-5$ and sequence identity $>20 \%$ ); only 11 genes are found to be unique to one of the two species. Because the four regions are derived from different scaffolds, they may belong to four distinct synteny blocks. All rearrangements described in the sections below occur within one of the four regions and, therefore, within a synteny block.

\section{Conserved non-eli genes are scattered in the eli gene cluster.}

In region I, the eli gene cluster comprises 15 members in $P$. sojae spanning $115 \mathrm{~kb}$ and 14 members in $P$. ramorum spanning $59 \mathrm{~kb}$. With the exception of one eli (i.e., ram5), all $P$. ramorum eli genes have orthologs in the region of conserved synteny in $P$. sojae (Jiang et al. 2006a). Soj5, the ram5 ortholog in $P$. sojae, is located on a different scaffold together with two other eli genes. Scattered among the 15 eli genes in $P$. ramorum are 5 non-eli genes. Homologs of two non-eli genes (JGI $P$. ramorum 78559 and 78560) are present elsewhere in the genome of $P$. sojae, but the other three are conserved in the $P$. sojae eli region. One of these (JGI P. ramorum 78562) has no hits with known proteins in GenBank, but the other two have. One (JGI P. ramorum 78572) shows highest BLASTX similarity to an inositol polyphosphate-4-phosphatase IP4P (AAB01069) with $E$ value $7 \mathrm{E}-32$ in the GenBank NR database, and the second (JGI P. ramorum 47328) to the phosphatidylinositol-glycan biosynthesis, class A (PIG-A) protein (P32363) with $E$ value 1E-109 in the SwissProt database. Both IP4P and PIG-A have functions related to the synthesis or metabolism of phospholipids and, hence, the conserved colocalization of the genes with eli genes is remarkable. There is, however, no indication that this has any biological relevance.

\begin{tabular}{|c|c|c|}
\hline Family or clade & Domain size (aa) & Conserved cysteine spacing pattern \\
\hline ELL-13 & $75-82$ & C-20-C-(12-17)-C-4-C-13-C-17/18-C \\
\hline GPex1 & 120 & C-C-30-C-16-C-31-C-30-C \\
\hline GPex2 & 300 & C-9-C-24-C-14-C-25-C-12-C-8-C-10-C-60-C-74-C-6-C-6-C-8-C-2-C-6-C \\
\hline
\end{tabular}

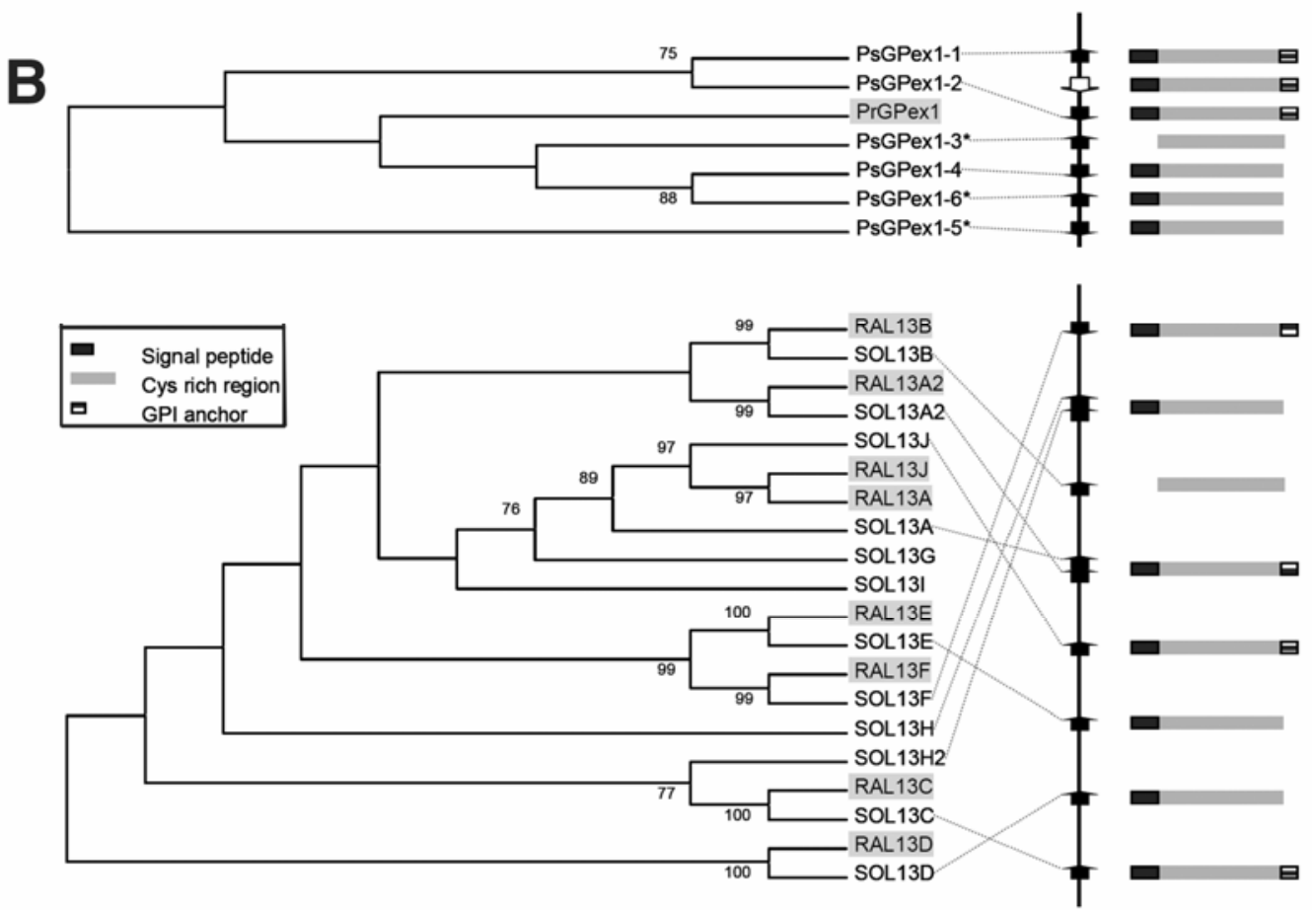

Fig. 2. A, Conserved cysteine (Cys) patterns in the three gene groups. B, Clustering of two gene groups encoding Cys-rich secreted proteins with a glycosylphosphatidylinositol (GPI) anchor. The phylogenetic trees are based on the Cys-rich domains. Proteins shaded in gray are derived from Phytophthora ramorum. The scaffolds depict the presence of ordered genes on P. sojae scaffold 3. Protein names in the phylogram are connected to their genes on the scaffold. The white arrow represents PsGPex2. RAL13A and RAL13A2 are two elicitin domains in one protein. The same holds for RAL13H and RAL13H3, and SOL13A and SOL13A2. 


\section{Clustering of three different families encoding Cys-rich secreted proteins.}

The ell13 genes that belong to one of the 17 clades in the complex elicitin family encode proteins that have a signal peptide, a Cys-rich elicitin domain, and a C-terminal tail with or without a glycosylphosphatidylinositol (GPI)-anchor signal (Jiang et al. 2006a). GPI anchoring is an important mechanism to tether extracellular proteins to the plasma membrane. The anchoring signal comprises a hydrophobic region at the extreme $\mathrm{C}$-terminus of the protein and can be predicted (Eisenhaber et al. 2003). In $P$. ramorum, all seven members (rall3A, rall3B, ral13C, rall3D, rall3E, rall3F, and rall3J) of the ell13 clade are located in region II and, in P. sojae, 8 (soll3A, soll3B, soll3C, soll3D, soll3E, soll3F, soll3H, and soll3J) of 10 ell13 genes are located in this region. The ELL-13 clade has a typical Cys spacing pattern (Fig. 2A) which, in three ELL-13
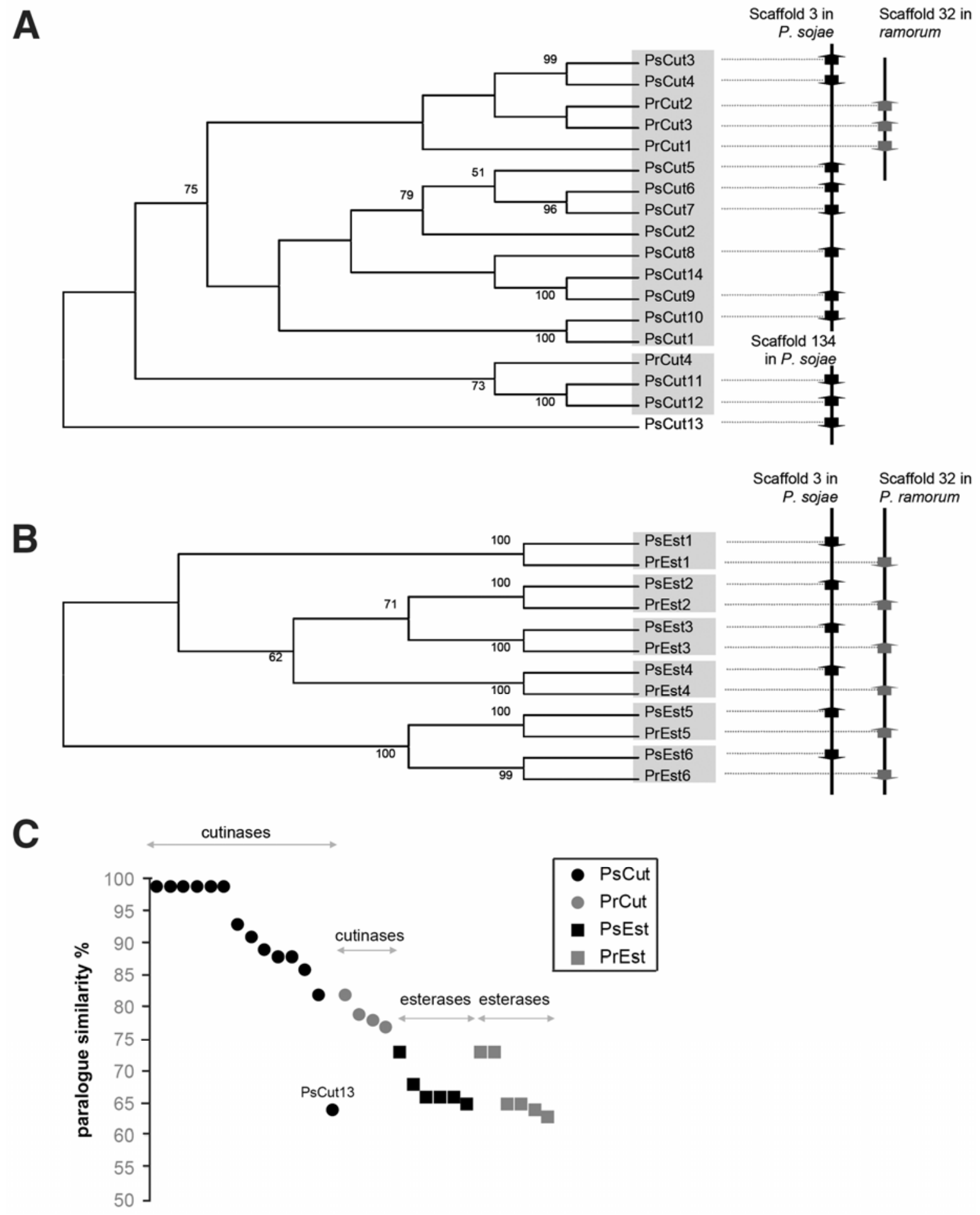

Fig. 3. A, Expansion of cutinase genes in scaffold 3 in Phytophthora sojae. B, Orthologs of each esterase gene in scaffold 32 in P. ramorum can be identified in scaffold 3 in $P$. sojae. Only esterase genes clustered in region I are included in the phylogenetic analysis. A and $\mathbf{B}$, Scaffolds depict the order and the orientation of the genes. Protein names in the phylogram are connected to their genes on the scaffold. C, Similarity of paralogs of cutinases and esterases. Among the cutinase genes, only PsCut 13 shows a relatively low level of similarity with its paralog. 

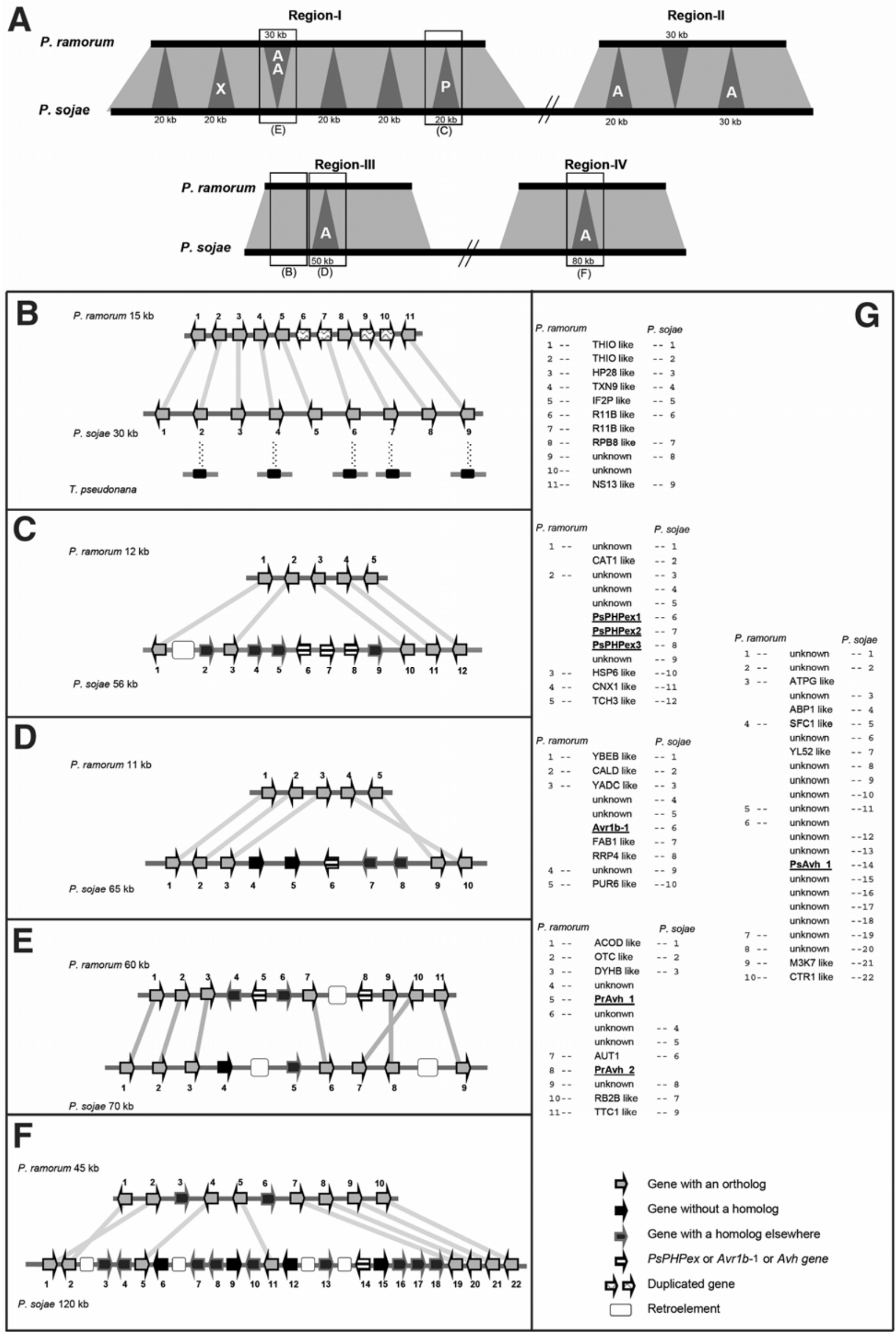
proteins (RAL13A, SOL13A, and SOL13H), occurs twice. The second domain is indicated by RAL13A2, SOL13A2, and $\mathrm{SOL} 13 \mathrm{H} 2$. A phylogenetic tree based solely on the elicitin domain (Fig. 2B) showed that all ELL-13 proteins encoded in region II have orthologs in both species. soll3G and sol13I, which are located on another scaffold, have no obvious othologs in $P$. ramorum; also, one of the two elicitin domains in SOL13H lacks an orthologous elicitin domain in P. ramorum. The elicitin domain RAL13A2 has an orthologous elicitin domain in $P$. sojae, SOL13A2, both encoded in region II. The conserved synteny of the ell13 gene clusters shows that the major expansion of the ELL-13 clade must have occurred before speciation.

Further downstream, there are other genes encoding Cysrich secreted proteins. Some of the encoded proteins have GPI anchors, like ELL-13; therefore, we named these genes GPex (GPI-anchored putative extracellular protein). Based on the Cys spacing pattern and the length, the proteins form two subgroups, GPex1 and GPex2 (Fig. 2A). The Cys-rich domains are located after the signal peptide. The proteins lack any typical conserved motif and have no homologs elsewhere in the Phytophthora genome or in other species. In $P$. ramorum, GPex1 and GPex2 are single-copy genes located within a 7-kb region and interspersed with ral13C. Also in $P$. sojae, GPex2 is a single-copy gene. In contrast, $P G e x l$ is a family consisting of six members and the single-copy PsGPex2 gene is located between two PsGPexl family members, PsGPexl-1 and PsGPex1-2. PsGPex1-3, PsGPex1-5, and PsGPex1-6 are pseudogenes carrying frameshift mutations, whereas PsGPexl-1, PsGPex1-2, and PsGPexl-4 each possess one intact open reading frame (ORF), two of which encode a GPI anchor. Also, PrGPex1 has a GPI anchor; however, strikingly, PrGPex2 lacks it, whereas its ortholog in P. sojae, PsGPex2, has it. When the Cys-rich domain was used to construct a phylogenetic tree, the expansion of GPexl in P. sojae became apparent (Fig. 2). The six PsGPexl genes do not form a single clade; to be so divergent, the PsGPexl genes should have evolved at a fast pace. Alternatively, the phylogenetic pattern could be explained by gene loss in $P$. ramorum. Transcripts of PsGPexl-2 and PsGPex 1-4 that belong to two different clades are present in the expressed sequence tag (EST) database, and ESTs also are found from $P s G P e x 2$.

\section{Expansion of a cutinase family versus conservation of an esterase family.}

Lipases and esterases constitute a large category of enzymes that possess a wide variety of structurally diverse substrates (Ollis et al. 1992). Two gene families encoding enzymes belonging to this category are located as clusters side by side in region I. The distance between the two clusters is approximately $50 \mathrm{~kb}$. One family encodes cutinases and the other a subclass of esterases. No apparent sequence homology can be found between these two gene families.

Cutinase is a member of the serine hydrolase family and is named after its ability to degrade cutin polymers (Longhi and Cambillau 1999). Region I contains a gene cluster encoding secreted proteins with a cutinase domain (IPR011150). In $P$. ramorum, the gene cluster comprises three genes (PrCutl,

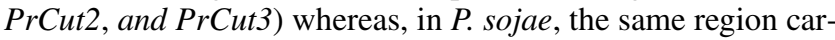
ries eight cutinase genes ( $\mathrm{PsCut} 3$ to $\mathrm{PsCut10}$ ). The expansion, however, is not limited to this region. A total of 14 members of this particular serine hydrolase family can be identified in the whole genome of $P$. sojae, whereas only 4 can be found in $P$. ramorum. All the cutinase genes have intact ORFs, and ESTs derived from PsCut1, PsCut10, PsCut12, and PsCut13 are present in the $P$. sojae EST database. In a phylogenetic tree that was constructed to visualize the relationship between the cutinase genes, two distinct clades can be identified (Fig. 3A). All PsCut genes and all PrCut genes assigned to the clusters on region I fall in one large clade, while the other, smaller clade contains Cut genes that are located on other scaffolds (scaffold 134 of $P$. sojae and scaffold 11 of $P$. ramorum). Apparently, the division of the two clades based on sequence similarity largely coincides with the different locations of the genes in the genome. The exceptions are three genes in the large clade, PsCut1, PsCut2, and PsCut14, that are located on two small scaffolds. It is very well possible that these small scaffolds become part of scaffold 3 in future sequence assemblies.

The esterase gene family located in region I comprises six members in $P$. sojae and six in P. ramorum (designated PsEst, and PrEst, respectively). The Est genes encode proteins with an esterase domain and lacking a signal peptide at the $\mathrm{N}$-terminus. The closest sequence match in the SwissProt database is a monoglyceride lipase (MGLL_RAT Q8R431) with a BLAST $E$ value of $1.8 \mathrm{E}-16$. They possess interpro domain IPR000379 and a search among all annotated Phytophthora proteins showed that Phytophthora spp. have a large family of more than 100 members, all possessing an esterase domain. The genes located in region I form a distinct subfamily, of which all members are located in one cluster. Phylogenetic reconstruction of the 12 esterases showed six groups (Fig. 3B). Each group comprises two proteins, one derived from $P$. sojae and the other from $P$. ramorum. The six groups indicate that each PrEst gene in $P$. ramorum clearly has an ortholog in $P$. sojae. In addition, gene order and orientation of the Est genes are conserved between the two species.

These analyses show that two neighboring gene families can have distinct evolutionary patterns. The gene family coding for extracellular cutinases is expanded in one of the two species, whereas the genes coding for intracellular esterases show similar duplication patterns in both species. One way to explain the pattern is to trace back the last duplication event. Gene duplication after speciation gives rise to similar copies (paralogs) within a species, whereas duplication events prior to speciation should result in divergent genes (orthologs) showing homology between species. Given a constant mutation rate, the time of the last duplication can be deduced from the similarity of paralogs. Nearly identical paralogs indicate a very recent duplication, whereas highly divergent paralogs indicate an older duplication. Within one genome, cutinase gene family members are more similar to each other than esterase gene family members are to each other (Fig. 3C). Recent duplications are indi-

Fig. 4. A, Indel blocks in regions of conserved synteny in Phytophthora sojae and P. ramorum. Indel blocks are shown as triangles. A refers to Avrlb-like genes, $\mathrm{P}$ to PsPHPex genes, and $\mathrm{X}$ to unknown genes. More detailed views of the rectangles $\mathrm{B}$ to $\mathrm{F}$ are shown below. $\mathrm{B}$, Conservation of gene order and orientation outside an indel block. The homologs in the diatom Thalassiosira pseudonana are on separate scaffolds. C, Insertion of the PsPHPex gene cluster in region I in $P$. sojae. D, Deletion of $A v r l b-1$ from $P$. ramorum (region III). E, Deletion of PrAvh_1 and PrAvh_2 from $P$. sojae (region I). F, Deletion of $P s A v h \_1$ from $P$. ramorum (region IV). B to $\mathbf{F}$, Length of the genes and the intergenic regions are not drawn on scale. $\mathbf{G}$, Gene names. B to E, Genes shown are listed next to the panels B to E; F, genes shown are listed on the right. The genes are named based on the best BLAST hit $(E$ value cutoff $<1 \mathrm{E}-5)$ in the SwissProt database. Homologs of genes are found based on TBLASTN hits ( $E$ value cutoff $<1$ E-5 and sequence identity $>40 \%$ ). $P s P H P e x$ and $A v r 1 b-1-1$ like genes are in bold and underlined. 
cated by high similarity ( $>75 \%$ ) of nearly all cutinase paralogs (PsCut13 is an exception). In contrast, all esterases have paralogs of 60 to $75 \%$ similarity, indicating older duplications, most likely prior to speciation. Moreover, the $P$. sojae $\mathrm{Cut}$ genes have been duplicated more recently than those of $P$. ramorum because the four cutinases of $P$. ramorum show lower similarity to their paralogs. Apparently, recent duplications have caused the expansion of the cutinase gene family in P. sojae.

\section{Regions of conserved synteny show loss or gain of genes and gene clusters.}

When the four regions of conserved synteny were analyzed for loss or gain of genes and gene clusters, each region appeared to contain at least one insertion or deletion block or indel block. In this study, an indel block is defined as a region containing three or more genes that lack homologs in the region of conserved synteny in the other species. The block sizes range in length from 20 to $80 \mathrm{~kb}$. Of the 11 indel blocks, 9 (comprising $280 \mathrm{~kb}$ in total) concern loss of genes in $P$. ramorum or gain of genes in $P$. sojae, whereas two blocks (60 $\mathrm{kb}$ in total) have the opposite pattern: loss in $P$. sojae or gain in P. ramorum (Fig. 4A).

To illustrate the conserved synteny, a region next to a $50-\mathrm{kb}$ indel block in region II is shown in Figure 4B. For all nine $P$. sojae genes distributed over a $30-\mathrm{kb}$ region, $P$. ramorum has orthologs. In $P$. ramorum, where the region spans only $15 \mathrm{~kb}$, two genes are duplicated, but the order and orientation of the nine genes are strictly conserved between the two genomes. When the nine genes were compared with BLAST against the diatom Thalassiosira pseudonana genome, five homologs were found on different scaffolds, and there was no conserved synteny (Fig. 4B).

One of the indel blocks contains a small gene cluster which comprises three genes located $103 \mathrm{~kb}$ downstream of the eli cluster in $P$. sojae. The program SignalP v2.0 predicts the three encoded proteins to be secreted (hidden Markov model [HMM] score $\geq 0.9$ ). The genes have no homologs in $P$. ramorum or in the extensive $P$. infestans EST databases; and the encoded proteins have an unusual amino acid composition with a very high content of His $(>19 \%)$ and Pro $(>44 \%)$. The average His and Pro composition in $P$. sojae proteins is 2 and $5 \%$, respectively (Table 1). The genes were named PsPHPex (P. sojae Pro/His-rich Phytophthora extracellular protein). PsPHPex2 is a pseudogene with frameshift mutations; the other two have intact ORFs. The 56-kb genomic region containing the PsPHPex gene cluster was compared with the 12kb syntenic region in $P$. ramorum (Fig. 4C). The genes flanking the PsPHPex family show conservation of gene order and orientation, whereas the PsPHPex genes, together with a few neighboring genes that also lack orthologs in $P$. ramorum, appear to be inserted in the genome of $P$. sojae or, from the point of view of $P$. ramorum, deleted from the syntenic region.

Table 1. Amino acid composition of the PsPHPex proteins ${ }^{\mathrm{a}}$

\begin{tabular}{lccccc}
\hline Name & $\begin{array}{l}\text { Size } \\
(\mathbf{a a})\end{array}$ & $\begin{array}{c}\text { Signal peptide } \\
\text { size (aa) }\end{array}$ & $\begin{array}{c}\text { Cys } \\
(\boldsymbol{\%})\end{array}$ & $\begin{array}{c}\text { His } \\
(\boldsymbol{\%})\end{array}$ & $\begin{array}{c}\text { Pro } \\
(\boldsymbol{\%})\end{array}$ \\
\hline PsPHPex1 & 275 & 18 & 0 & 19 & 44 \\
PsPHPex2 $^{\mathrm{b}}$ & 284 & 18 & 0 & 28 & 47 \\
PsPHPex3 & 265 & 18 & 0 & 21 & 45 \\
Avg protein & 491 & $\ldots$ & 2 & 2 & 5 \\
\hline
\end{tabular}

${ }^{a}$ Average protein composition (Avg protein) was calculated from 19,276 $P$. sojae protein sequences; $\mathrm{aa}=$ amino $\mathrm{acid}, \mathrm{Cys}=$ cysteine, $\mathrm{His}=$ histidine, and Pro $=$ proline .

${ }^{\mathrm{b}}$ PsPHPex2 is a pseudogene; the protein sequence was obtained after correction of the frameshift mutations.
Avr $1 b-1$ and its five homologs all reside in indel blocks.

The four regions of conserved synteny contain six genes encoding RXLR-dEER proteins. Remarkably, all six RXLRdEER genes (i.e., $A v r l b-1$ and five $A v h$ genes) reside in one of the indel blocks (Fig. 4A), and a $\chi^{2}$ test with one degree of freedom $(P<0.01)$ showed that this is significant based on the fact that approximately $15 \%$ of the sequences covering the four regions are represented by indel blocks. The indel block containing Avrlb-1 is located in region III and the one containing $P s A v h \_1$, the closest homologue of $A v r l b-1$ in $P$. sojae (89.1\% similarity at protein level), is located in region IV. Three indel blocks are found in region II, two of which contain the $P$. sojae Avh genes PsAvh_22 and PsAvh_45. Finally, one of the six indel blocks present in region I contains two $P$. ramorum Avh genes, PrAvh_1 and PrAvh_2, which are the closest homologs of $A v r 1 b-1$ in $P$. ramorum (23.1 and $22.1 \%$, respectively, at protein level).

Close examination of region III showed that a $65-\mathrm{kb}$ fragment in $P$. sojae contains five genes that are present in nearly the same order within an $11-\mathrm{kb}$ fragment in $P$. ramorum. However, $P$. sojae has a $50-\mathrm{kb}$ insert containing five genes, including $A v r l b-1$, that are absent in $P$. ramorum (Fig. 4D). Similarly, analysis of region IV shows that a genomic sequence of $80 \mathrm{~kb}$ containing four retroelements and 14 genes, including PsAvh_l, is missing from the genome of P. ramorum (Fig. 4F). The corresponding region in $P$ ramorum contains two genes that have no orthologs in $P$. sojae, but lacks retroelements.

In $P$. ramorum, PrAvh_1 and PrAvh_2 are located in the vicinity of the eli genes in region I at a distance of approximately $30 \mathrm{~kb}$. A $60 \mathrm{~kb}$ region in $P$. ramorum containing these two genes is syntenic with a $70-\mathrm{kb}$ region in $P$. sojae, and seven pairs of orthologs can be identified. Genes directly flanking PrAvh_2 are conserved between the two species, but those flanking PrAvh_l are not. The regions containing PrAvh_l and $P r A v h \_2$ are absent from the $P$. sojae genome or replaced by other sequences and, in both $P$. ramorum and $P$. sojae, retroelements are found in the rearranged regions. A $30-\mathrm{kb} P$. ramorum sequence appears to be deleted from the syntenic region in $P$. sojae (Fig. 4E).

\section{DISCUSSION}

Genomewide analyses of the draft genome sequences of $P$. sojae and $P$. ramorum performed by Tyler and associates (2006) revealed high levels of colinearity and showed that the majority of the predicted genes in these two related plant pathogens form groups of homologous proteins. Less than $10 \%$ of the genes in $P$. sojae and $4 \%$ in $P$. ramorum have no homolog in the other genome, and the two species have 9,768 pairs of orthologous genes (Tyler et al. 2006). In this study, we analyzed four genomic regions that cover only a very small part of the two genomes: 1.6 and $1.4 \%$ of the $P$. sojae and $P$. ramorum genome, respectively. Less than $2 \%$ of the orthologous gene pairs $(n=192)$ are located in these regions. Nevertheless, we found several interesting examples of genome rearrangements, such as deletions (or insertions) and gene duplications. Different types of genome rearrangements were found next to each other and often were associated with genes encoding secreted proteins, including effectors that are important for interaction with host plants. Region I, for example, nicely illustrates contrasting patterns between genes encoding different types of secreted proteins: those coding for elicitins are conserved in the two species, those coding for extracellular cutinases are expanded in one of the two, and those coding for RXLR-dEER proteins are highly specific for one of the two and always located in indel blocks. This suggests that mutation and ectopic recombination have occurred throughout the region. Natural 
selection and genetic drift may have caused loss of some changes, whereas other changes were retained, and it is likely that adaptive advantages or disadvantages gave rise to such contrasting evolutionary patterns.

The level of conserved synteny reflects the divergence of the two Phytophthora genomes. In the four investigated regions, gene order and orientation were largely conserved, with only $15 \%$ of the orthologue pairs showing either position or direction reversal. Because the regions were not randomly chosen, other regions in the genome may show different levels of conserved synteny. In another study, we compared $127 \mathrm{~kb}(36$ genes) in $P$. sojae surrounding the Ps 3.4 gene with $93 \mathrm{~kb}(32$ genes) in $P$. ramorum and observed a much higher level of conserved synteny: over $90 \%$ of the genes could be assigned as orthologs and very few reversals were found (Jiang et al. 2006b). The same was true for regions surrounding a highly conserved G-protein-coupled receptor gene (R. H. Y. Jiang, I. Sama, and F. Govers, unpublished). Regions of lower level of conserved synteny also have been found (unpublished data). The overall colinearity confirms that the two genomes are reasonably similar and demonstrates that the evolutionary distance between the two Phytophthora spp. is appropriate to find lineage specific gene duplications and deletions.

For pathogens, pathogenicity-related genes are responsible for the parasitic life style. They often evolve at a faster pace than genes with housekeeping functions. The rice blast pathogen Magnaporthe grisea and the bread mold fungus Neurospora crassa, two filamentous ascomycetes that diverged approximately 200 million years ago, have some regions with microsynteny but lack extensive regions of conserved synteny (Hamer et al. 2001). However, several gene families present in both species appeared to be expanded in $M$. grisea and many of these encode proteins associated with pathogenicity, such as cutinases, subtilisin-like serine proteases, and Cys-rich polypeptides (Dean et al. 2005). P. sojae and $P$. ramorum exhibit differences in host specificity: $P$. sojae is a specialized pathogen on soybean, whereas $P$. ramorum has a very broad host range. This biological difference may be reflected in their pathogenicity-related genes, and the expansion of cutinase genes could be an example. Cutinase and esterase gene families are located adjacent to one another in the genome, but the localization of the proteins is different; the cutinases are predicted to be secreted, whereas the esterases remain inside the cell. The expansion of the cutinase genes in $P$. sojae is in sharp contrast to the neighboring esterase gene family, which exhibits a highly conserved pattern. Cutinases are produced by phytopathogenic fungi and by pollen to hydrolyze ester bonds in the cutin polymer. In pathogenic fungi, cutinases are secreted by penetration hyphae to assist in entering the cuticle (Kolattukudy et al. 1995). Disruption of a cutinase gene in Fusarium solani f. sp. pisi decreased its virulence by more than $50 \%$ (Dantzig et al. 1986). Cutinases in Phytophthora spp. also may be related to virulence. Adaptation to perform enzymatic tasks at the host surface may be the cause of the frequent duplications of cutinase genes observed in $P$. sojae.

Regions I and II were selected because they contain genes belonging to the extensive Phytophthora-specific elicitin gene family. The four ELI clades (on region I) are the most conserved groups in the elicitin family, whereas the ELL-13 clade (on region II) is the most divergent group (Jiang et al. 2006a). Despite their sequence diversity, the ELL-13 members share common features, such as a predicted signal peptide, a Cysrich domain, and, in some cases, a predicted GPI anchor. It is striking that several other genes encoding secreted proteins with Cys-rich domains and GPI anchors are located in close proximity to the ell13 genes. The close physical distance between these genes and the ell13 gene cluster is conserved in the two genomes, but the gene number is not. In $P$. sojae, the GPexl family is expanded, whereas $P$. ramorum has only one copy. These genes belong to a much larger group of Phytophthora genes encoding glycosylated GPI-anchored proteins. A preliminary search showed that approximately 100 genes in $P$. sojae and 90 in $P$. ramorum code for proteins with a predicted GPI anchor, and many of them occur in clusters in the genome. These surface proteins often contain repeat-like sequences and are rapidly evolving, suggesting that they play a role in interactions with host plants (Jiang 2006). GPI anchors link proteins or polysaccharides to a membrane. A wide range of possible roles has been suggested for GPI membrane anchors, including a space-filling role in the cell coating, shedding and turnover of membrane proteins, signal transduction, and intracellular targeting (Thomas et al. 1990). GPI-anchored proteins are ubiquitous in eukaryotes and also exist in some Archaebacteria, such as Sulfolobus (Ikezawa 2002). Some pathogens specialize in the synthesis of GPI-anchored proteins. The cell surface of trypanosomes, for example, is enveloped by a dense coat comprising millions of variant GPI-anchored surface glycoproteins (Overath and Engstler 2004). In several ascomycetous fungi, the majority of the proteins isolated by a procedure aimed at identifying covalently linked cell wall proteins have a GPI anchor (de Groot et al. 2004). In a recent study, Meijer and associates (2006) applied the same isolation procedure to characterize covalently linked cell wall proteins in mycelium of $P$. ramorum. Remarkably, none of the identified proteins contained a GPI anchor and this suggests that, in Phytophthora spp., GPI-anchored proteins preferably are retained in the membrane. Expression analysis of the eli and ell genes revealed that genes of the ELL-3 clade are highly expressed in motile zoospores and not in mycelium (Jiang et al. 2006a). Similar to ELL-13, several of the ELL-3 proteins have a GPI anchor. Because zoospores lack cell walls, it is conceivable that they are covered by GPI-anchored proteins (Jiang et al. 2006a).

Gene rearrangement of virulence-related genes probably is a common theme in the genome evolution of pathogens. In plant pathogens, avirulence gene products are able to interact with host resistance gene products with high levels of specificity, and they can undergo co-evolution with their hosts (Stahl and Bishop 2000). Avr genes can be expected to belong to the most rapidly evolving genes in a pathogen. Loss of $A v r$ genes to evade host detection has been described in several plant-pathogenic fungi (Rohe et al. 1995; van Kan et al. 1991; Westerink et al. 2004), and genome rearrangements in unstable repeatrich, subtelomeric regions and transposon insertions generating new virulent alleles also have been reported (Orbach et al. 2000). In this study, regions III and IV were selected because they contain the cultivar-specific $A v r$ gene $A v r l b-1$ and its closest homolog in $P$. sojae, PsAvh_l. In the four regions, we found four additional genes that, like Avrlb-1 and PsAvh_l, belong to the RXLR-dEER superfamily. All six appeared to be absent in the other genome, demonstrating that the loci containing these genes have been rearranged, resulting in loss or gain of genetic information. A similar situation was observed at the Avr3a locus in $P$. infestans, which resides in a region that is colinear with the region containing the ATRl gene in H. parasitica (Armstrong et al. 2005). In $H$. parasitica, a region of $125 \mathrm{~kb}$ surrounding Avr3a is absent but replaced by a region of similar size containing ATRl which, in turn, is absent in $P$. infestans. Because AVR1b-1, Avr3a, and ATR1 are cultivar- or ecotype-specific avirulence determinants, it is likely that the ancestral genes have been through high selection pressure during the interaction with plants and, as a result, are highly divergent from their closest homolog in other oomycete species with a different host range. Due to selection pressure, the genomic regions carrying these Avr genes may accumulate muta- 
tions and rearrangements, eventually leading to deletion of the gene. Deletion of the five $A v h$ genes suggests a similar scenario of host selection pressure. From all $A v h$ genes that are currently identified in the two sequenced Phytophthora genomes, the vast majority shows frequent deletions (unpublished results; Tyler et al. 2006) and this supports the observation that genes encoding RXLR-dEER proteins are located in highly dynamic genomic regions.

In the four regions, we found a number of mobile elements; however, none of them showed conserved gene order or orientation. Because their localization and orientation are largely random, they do not seem to follow the same evolutionary history as genes. Most likely, mobile elements have a more recent expansion. For example, in wheat and rice, different retrotransposons invaded the genomes repeatedly over time and created species-, genera-, and family-specific repeats. The genome size difference between these two monocots mainly is due to occurrence of retrotransposons (Sandhu and Gill 2002). In this study, more mobile elements were found in $P$. sojae than in $P$. ramorum, and this is representative for the whole genome ( $\mathrm{R}$. H. Y. Jiang, unpublished data). Their higher abundance in $P$. sojae may be responsible for the larger genome size. A few of the mobile elements were found to reside in the indel blocks, and it is tempting to speculate that mobile elements play a role in causing the rearrangements. The extent to which mobile elements contribute to the plasticity of Phytophthora genomes needs further investigation.

\section{MATERIALS AND METHODS}

\section{Genome databases.}

The genomic sequences and annotated protein sequences of P. sojae (version1), P. ramorum (version1), and of the diatom T. pseudonana (Armbrust et al. 2004) were obtained from the website of the United States Department of Energy JGI.

\section{Ortholog search and determination of conserved synteny.}

The regions of conserved synteny were first roughly obtained from PhIGs (Dehal and Boore 2006). The elicitin and ell13 sequences were identified by Jiang and associates (2006a). The Avrlb-1 sequence was retrieved from GenBank (AAR05402). The homologs of Avrlb-1 were determined by BLASTP comparison of Avrlb-1 against whole-genome sequences in $P$. sojae and $P$. ramorum. The surrounding genomic regions of the effector-like genes were extracted. Subsequently, every gene in the investigated region was compared with BLAST analysis against all the genes in the other genome; if gene pairs from two genomes shared best reciprocal BLAST hits and were located in regions of conserved synteny, they were assigned as orthologs. Orthologs also were assigned if gene pairs shared best reciprocal BLAST hits and their pairing was supported by phylogenetic analysis. Mobile elements generally do not have homologs in the syntenic regions, and they were not analyzed.

\section{Bioinformatics tools.}

Sequences were analyzed with the Vector NTI 8 package. Multiple sequence alignment was performed using ClustalX v1.8, and Molecular Evolutionary Genetic Analysis v2.1 (MEGA) (Kumar et al. 2001) was used for phylogenetic tree construction. Maximum Parsimony (MP) was used to construct phylogenetic trees and the heuristic search (Close-NeighborInterchange) method was used as specified in the program MEGA. The inferred phylogeny was tested by 1,000 bootstrap replicates. Dot plots were made using the program PipMaker (Schwartz et al. 2000). If alignments showed at least 100-bp homology with a nucleotide identity $>70 \%$, the homologous stretch was plotted. For BLAST searches, we used the NCBI BLAST program and standalone BLAST v2.2.3 (Altschul et al. 1997). Signal peptides were predicted by SignalP v2.0 (Krogh et al. 2001). They were predicted by two criteria adapted and described by Torto and associates (2003): i) SignalP-HMM prediction is positive with a score $>0.9$, and ii) SignalP-neural network predicts a cleavage site between 10 and 30 amino acids in length. For GPI anchor prediction, big-PI Plant Predictor (Eisenhaber et al. 2003) was used. Calculation scripts were written in Python 2.2 and are available from the authors upon request.

\section{ACKNOWLEDGMENTS}

This work was financially supported by grants to F. Govers from NWOAspasia (015.000.057) and EU-BioExploit (FOOD-CT-2005-513959), a travel grant to R. H. Y. Jiang from the Technology Foundation STW for attending the Phytophthora annotation jamboree, and a long-term fellowship from the Netherlands Genomics Initiative to R. H. Y. Jiang (NGI 05072-404). Special thanks to D. Baker and M. C. Chibucos for assistance with preparation and editing of the manuscript.

\section{LITERATURE CITED}

Allen, R. L., Bittner-Eddy, P. D., Grenville-Briggs, L. J., Meitz, J. C., Rehmany, A. P., Rose, L. E., and Beynon, J. L. 2004. Host-parasite coevolutionary conflict between Arabidopsis and downy mildew. Science 306:1957-1960.

Altschul, S. F., Madden, T. L., Schaffer, A. A., Zhang, J. H., Zhang, Z., Miller, W., and Lipman, D. J. 1997. Gapped BLAST and PSI-BLAST: A new generation of protein database search programs. Nucleic Acids Res. 25:3389-3402.

Armbrust, E. V., Berges, J. A., Bowler, C., Green, B. R., Martinez, D., Putnam, N. H., Zhou, S. G., Allen, A. E., Apt, K. E., Bechner, M., Brzezinski, M. A., Chaal, B. K., Chiovitti, A., Davis, A. K., Demarest, M. S., Detter, J. C., Glavina, T., Goodstein, D., Hadi, M. Z., Hellsten, U., Hildebrand, M., Jenkins, B. D., Jurka, J., Kapitonov, V. V., Kroger, N., Lau, W. W. Y., Lane, T. W., Larimer, F. W., Lippmeier, J. C., Lucas, S., Medina, M., Montsant, A., Obornik, M., Parker, M. S., Palenik, B., Pazour, G. J., Richardson, P. M., Rynearson, T. A., Saito, M. A., Schwartz, D. C., Thamatrakoln, K., Valentin, K., Vardi, A., Wilkerson, F. P., and Rokhsar, D. S. 2004. The genome of the diatom Thalassiosira pseudonana: Ecology, evolution, and metabolism. Science 306:79-86.

Armstrong, M. R., Whisson, S. C., Pritchard, L., Bos, J. I., Venter, E., Avrova, A. O., Rehmany, A. P., Bohme, U., Brooks, K., Cherevach, I., Hamlin, N., White, B., Fraser, A., Lord, A., Quail, M. A., Churcher, C., Hall, N., Berriman, M., Huang, S., Kamoun, S., Beynon, J. L., and Birch, P. R. 2005. An ancestral oomycete locus contains late blight avirulence gene Avr3a, encoding a protein that is recognized in the host cytoplasm. Proc. Natl. Acad. Sci. U.S.A. 102:7766-7771.

Birch, P. R., Rehmany, A. P., Pritchard, L., Kamoun, S., and Beynon, J. L. 2006. Trafficking arms: Oomycete effectors enter host plant cells. Trends Microbiol. 14:8-11.

Buchrieser, C., Rusniok, C., Kunst, F., Cossart, P., and Glaser, P. 2003. Comparison of the genome sequences of Listeria monocytogenes and Listeria innocua: Clues for evolution and pathogenicity. FEMS (Fed. Eur. Microbiol. Soc.) Immunol. Med. Microbiol. 35:207-213.

Carlton, J., Silva, J., and Hall, N. 2005. The genome of model malaria parasites, and comparative genomics. Curr. Issues Mol. Biol. 7:23-37.

Cooke, D. E., Drenth, A., Duncan, J. M., Wagels, G., and Brasier, C. M. 2000. A molecular phylogeny of Phytophthora and related oomycetes. Fungal Genet. Biol. 30:17-32.

Dantzig, A. H., Zuckerman, S. H., and Andonov-Roland, M. M. 1986. Isolation of a Fusarium solani mutant reduced in cutinase activity and virulence. J. Bacteriol. 168:911-916.

Dean, R. A., Talbot, N. J., Ebbole, D. J., Farman, M. L., Mitchell, T. K., Orbach, M. J., Thon, M., Kulkarni, R., Xu, J. R., Pan, H., Read, N. D., Lee, Y. H., Carbone, I., Brown, D., Oh, Y. Y., Donofrio, N., Jeong, J. S., Soanes, D. M., Djonovic, S., Kolomiets, E., Rehmeyer, C., Li, W., Harding, M., Kim, S., Lebrun, M. H., Bohnert, H., Coughlan, S., Butler, J., Calvo, S., Ma, L. J., Nicol, R., Purcell, S., Nusbaum, C., Galagan, J. E., and Birren, B. W. 2005. The genome sequence of the rice blast fungus Magnaporthe grisea. Nature 434:980-986.

de Groot, P. W. J., de Boer, A. D., Cunningham, J., Dekker, H. L., de Jong, L., Hellingwerf, K. J., de Koster, C., and Klis, F. M. 2004. Proteomic analysis of Candida albicans cell walls reveals covalently bound carbohydrate-active enzymes and adhesins. Eukaryotic Cell 3:955-965. 
Dehal, P. S., and Boore, J. L. 2006. A phylogenomic gene cluster resource: The Phylogenetically Inferred Groups (PhIGs) database. BMC Bioinformatics 7:201.

Eisenhaber, B., Wildpaner, M., Schultz, C. J., Borner, G. H., Dupree, P., and Eisenhaber, F. 2003. Glycosylphosphatidylinositol lipid anchoring of plant proteins. Sensitive prediction from sequence- and genome-wide studies for Arabidopsis and rice. Plant Physiol. 133:1691-1701.

El-Sayed, N. M., Myler, P. J., Blandin, G., Berriman, M., Crabtree, J., Aggarwal, G., Caler, E., Renauld, H., Worthey, E. A., Hertz-Fowler, C., Ghedin, E., Peacock, C., Bartholomeu, D. C., Haas, B.J., Tran, A.-N., Wortman, J. R., Alsmark, U. C. M., Angiuoli, S., Anupama, A., Badger, J., Bringaud, F., Cadag, E., Carlton, J. M., Cerqueira, G. C., Creasy, T., Delcher, A. L., Djikeng, A., Embley, T. M., Hauser, C., Ivens, A. C., Kummerfeld, S. K., Pereira-Leal, J. B., Nilsson, D., Peterson, J., Salzberg, S. L., Shallom, J., Silva, J. C., Sundaram, J., Westenberger, S., White, O., Melville, S. E., Donelson, J. E., Andersson, B., Stuart, K. D., and Hall, N. 2005. Comparative genomics of Trypanosomatid parasitic protozoa. Science 309:404-409.

Erwin, D. C., and Ribeiro, O. K. 1996. Phytophthora Diseases Worldwide. The American Phytopathological Society, St. Paul, MN, U.S.A.

Frazer, K. A., Elnitski, L., Church, D. M., Dubchak, I., and Hardison, R. C. 2003. Cross-species sequence comparisons: A review of methods and available resources. Genome Res. 13:1-12.

Hamer, L., Pan, H., Adachi, K., Orbach, M. J., Page, A., Ramamurthy, L., and Woessner, J. P. 2001. Regions of microsynteny in Magnaporthe grisea and Neurospora crassa. Fungal Genet. Biol. 33:137-143.

Ikezawa, H. 2002. Glycosylphosphatidylinositol (GPI)-anchored proteins. Biol. Pharm. Bull. 25:409-417.

Jiang, R. H. Y. 2006. Footprints of Evolution: The Dynamics of Effector Genes in the Phytophthora Genome. Ph.D. thesis. Wageningen University, Wageningen, The Netherlands.

Jiang, R. H. Y., Tyler, B. M., Whisson, S. C., Hardham, A. R., and Govers, F. 2006a. Ancient origin of elicitin gene clusters in Phytophthora genomes. Mol. Biol. Evol. 23:338-351.

Jiang, R. H. Y., Weide, R., van de Vondervoort, P. I. J., and Govers, F 2006b. Amplification generates modular diversity at an avirulence locus in the pathogen Phytophthora. Genome Res. 16:827-840.

Kamoun, S. 2006. A catalogue of the effector secretome of plant pathogenic oomycetes. Annu. Rev. Phytopathol. 44:41-60.

Kamoun, S., van West, P., Vleeshouwers, V. G. A. A., de Groot, K. E., and Govers, F. 1998. Resistance of Nicotiana benthamiana to Phytophthora infestans is mediated by the recognition of the elicitor protein INF1. Plant Cell 10:1413-1425.

Kolattukudy, P. E., Rogers, L. M., Li, D., Hwang, C. S., and Flaishman, M. A. 1995. Surface signaling in pathogenesis. Proc. Natl. Acad. Sci. U.S.A. 92:4080-4087.

Krogh, A., Larsson, B., von Heijne, G., and Sonnhammer, E. L. L. 2001 Predicting transmembrane protein topology with a hidden Markov model: Application to complete genomes. J. Mol. Biol. 305:567-580

Kumar, S., Tamura, K., Jakobsen, I. B., and Nei, M. 2001. MEGA2: Molecular evolutionary genetics analysis software. Bioinformatics 17:1244-1245.

Longhi, S., and Cambillau, C. 1999. Structure-activity of cutinase, a small lipolytic enzyme. Biochim. Biophys. Acta Mol. Cell Biol. Lipids 1441:185-196.

McCouch, S. R. 2001. Genomics and synteny. Plant Physiol. 125:152-155.

Meijer, H. J. G., van de Vondervoort, P. J. I., Yin, Q. Y., de Koster, C. G., Klis, F. M., Govers, F., and de Groot, P. W. J. 2006. Identification of cell wall-associated proteins from Phytophthora ramorum. Mol. PlantMicrobe Interact. 19:1348-1358.

Mikes, V., Milat, M. L., Ponchet, M., Ricci, P., and Blein, J. P. 1997. The fungal elicitor cryptogein is a sterol carrier protein. FEBS (Fed. Eur. Biochem. Soc.) Lett. 416:190-192.

Nespoulous, C., Gaudemer, O., Huet, J. C., and Pernollet, J. C. 1999 Characterization of elicitin-like phospholipases isolated from Phytophthora capsici culture filtrate. FEBS (Fed. Eur. Biochem. Soc.) Lett. 452:400-406

Ollis, D. L., Cheah, E., Cygler, M., Dijkstra, B., Frolow, F., Franken, S. M., Harel, M., Remington, S. J., Silman, I., Schrag, J., Sussman, J. L., Verschueren, K. H. G., and Goldman, A. 1992. The alpha/beta hydrolase fold. Protein Eng. 5:197-211.

Orbach, M. J., Farrall, L., Sweigard, J. A., Chumley, F. G., and Valent, B. 2000. A telomeric avirulence gene determines efficacy for the rice blast resistance gene $\mathrm{Pi}$-ta. Plant Cell 12:2019-2032.

Overath, P., and Engstler, M. 2004. Endocytosis, membrane recycling and sorting of GPI-anchored proteins: Trypanosoma brucei as a model sys- tem. Mol. Microbiol. 53:735-744.

Rehmany, A. P., Gordon, A., Rose, L. E., Allen, R. L., Armstrong, M. R., Whisson, S. C., Kamoun, S., Tyler, B. M., Birch, P. R., and Beynon, J. L. 2005. Differential recognition of highly divergent downy mildew avirulence gene alleles by $R P P 1$ resistance genes from two Arabidopsis lines. Plant Cell 17:1839-1850.

Ricci, P., Trentin, F., Bonnet, P., Venard, P., Moutonperronnet, F., and Bruneteau, M. 1992. Differential production of parasiticein, an elicitor of necrosis and resistance in tobacco, by isolates of Phytophthora Parasitica. Plant Pathol. 41:298-307.

Rizzo, D. M., Garbelotto, M., and Hansen, E. M. 2004. Phytophthora ramorum: Integrative research and management of an emerging pathogen in California and Oregon forests. Annu. Rev. Phytopathol.

Rohe, M., Gierlich, A., Hermann, H., Hahn, M., Schmidt, B., Rosahl, S., and Knogge W. 1995. The race-specific elicitor, NIP1, from the barley pathogen, Rhynchosporium secalis, determines avirulence on host plants of the Rrs 1 resistance genotype. EMBO (Eur. Mol. Biol. Organ.) J. 14:4168-4177.

Sandhu, D., and Gill, K. S. 2002. Gene-containing regions of wheat and the other grass genomes. Plant Physiol. 128:803-811.

Schwartz, S., Zhang, Z., Frazer, K. A., Smit, A., Riemer, C., Bouck, J. Gibbs, R., Hardison, R., and Miller, W. 2000. PipMaker-a web server for aligning two genomic DNA sequences. Genome Res. 10:577-586.

Shan, W., Cao, M., Leung, D., and Tyler, B. M. 2004. The Avr1b locus of Phytophthora sojae encodes an elicitor and a regulator required for avirulence on soybean plants carrying resistance gene Rps $1 b$. Mol Plant-Microbe Interact. 17:394-403.

Stahl, E. A., and Bishop, J. G. 2000. Plant-pathogen arms races at the molecular level. Curr. Opin. Plant Biol. 3:299-304.

Thomas, J. R., Dwek, R. A., and Rademacher, T. W. 1990. Structure, biosynthesis, and function of glycosylphosphatidylinositols. Biochemistry 29:5413-5422.

Torto, T. A., Li, S., Styer, A., Huitema, E., Testa, A., Gow, N. A., van West, P., and Kamoun, S. 2003. EST mining and functional expression assays identify extracellular effector proteins from the plant pathogen Phytophthora. Genome Res. 13:1675-1685.

Tyler, B. M., Tripathy, S., Zhang, X., Dehal, P., Jiang, R. H. Y., Aerts, A., Arredondo, F., Baxter, L., Bensasson, D., Beynon, J. L., Damasceno, C. M. B., Dickerman, A., Dorrance, A. E., Dou, D., Dubchak, I., Garbelotto, M., Gijzen, M., Gordon, S., Govers, F., Grunwald, N. J., Huang, W., Ivors, K., Jones, R. W., Kamoun, S., Krampis, K., Lamour, K., Lee, M.K., McDonald, W. H., Medina, M., Meijer, H. J. G., Nordberg, E., Maclean, D. J., Ospina-Giraldo, M. D., Morris, P. F., Phuntumart, V., Putnam, N., Rash, S., Rose, J. K. C., Sakihama, Y., Salamov, A., Savidor, A., Scheuring, C., Smith, B., Sobral, B. W. S., Terry, A., TortoAlalibo, T., Win, J., Xu, Z., Zhang, H., Grigoriev, I., Rokhsar, D., and Boore, J. 2006. Phytophthora genome sequences uncover evolutionary origins and mechanisms of pathogenesis. Science. 313:1261-1266.

van Kan, J. A. L., van den Ackerveken, G. J. M., and de Wit, P. J. G. M. 1991. Cloning and characterization of cDNA of avirulence gene Avr 9 of the fungal pathogen Cladosporium fulvum, causal agent of tomato leaf mold. Mol. Plant-Microbe Interact. 4:52-59.

Van't Slot, K. A. E., and Knogge, W. 2002. A dual role for microbial pathogen-derived effector proteins in plant disease and resistance. Crit. Rev. Plant Sci. 21:229-271.

Vauthrin, S., Mikes, V., Milat, M. L., Ponchet, M., Maume, B., Osman, H., and Blein, J. P. 1999. Elicitins trap and transfer sterols from micelles, liposomes and plant plasma membranes. Biochim. Biophys. Acta Biomembr. 1419:335-342.

Westerink, N., Brandwagt, B. F., de Wit, P. J. G. M., and Joosten, M. H. 2004. Cladosporium fulvum circumvents the second functional resistance gene homologue at the $C f-4$ locus $(H c r 9-4 E)$ by secretion of a stable avr4E isoform. Mol. Microbiol. 54:533-545.

\section{AUTHOR-RECOMMENDED INTERNET RESOURCES}

DOE Joint Genome Institute (JGI) P. ramorum genome database: genome.jgi-psf.org/ramorum1/ramorum1.home.html

DOE JGI $P$. sojae genome database: genome.jgi-psf.org/sojae1/sojae1.home.htm

PhIGs (Phylogenetically Inferred Groups) webpage: www.phigs.org Python software website: www.python.org

United States Department of Energy JGI: www.jgi.doe.gov

The Virginia Bioinformatics Institute (VBI) microbial database: phytophthora.vbi.vt.edu 